\title{
Urinary Incontinence: Sphincter Functioning from a Urological Perspective
}

\author{
John P.F.A. Heesakkers Reza R.R. Gerretsen \\ Department of Urology, UMC St Radboud Nijmegen, Nijmegen, The Netherlands
}

\section{Key Words}

Urinary incontinence - Urethral sphincter .

Electromyography $\cdot$ Intrinsic sphincter deficiency

\begin{abstract}
Stress urinary incontinence (SUI) is a debilitating disorder caused by malfunctioning of the urethral sphincter. Anatomical and histological properties of the sphincter, its innervation and supporting structures are explained in relation to the closing mechanism of the bladder outlet. Urethral sphincter function is discussed from the passive concept of urethral pressure transmission to the 'hammock theory' and the role of the pubococcygeus muscles. SUI is caused by a combination of intrinsic sphincter deficiency and urethral hypermobility. The difficult interpretation of the parameters in urodynamic investigation to assess intrinsic sphincter deficiency (ISD) and/or urethral hypermobility is discussed. Electromyography (EMG) is valuable in the assessment of the overall urethral sphincter in relation to maneuvers (kinesiological EMG) and at the level of the muscle fiber (needle EMG). The diagnostic potential of circumferential surface EMG in the urethral sphincter is reviewed in relation to the EMG features of ISD.
\end{abstract}

Copyright $@ 2004$ S. Karger AG, Basel

Supported by a grant from the European Community (QLRT-200100218).

\begin{tabular}{ll}
\hline KARGER & ( ) 2004 S. Karger AG, Basel \\
Fax +41612-2823/04/0692-0093\$21.00/0 \\
$\begin{array}{l}\text { E-Mail karger@ 12 34 karger.ch } \\
\text { www.karger.com }\end{array}$ & $\begin{array}{l}\text { Accessible online at: } \\
\text { www.karger.com/dig }\end{array}$
\end{tabular}

\section{Introduction}

Urinary incontinence is a debilitating disorder, with an extensive impact on quality of life. It is a common and distressing disorder, which affects mostly the elderly.

Incontinence may take various forms: urge incontinence, stress incontinence and mixed incontinence are the three main types. Urge incontinence is the involuntary loss of urine associated with a strong desire to void. Patients with urge incontinence are characterized by frequent micturition accompanied by an urge to void. Stress urinary incontinence is a condition of involuntary urine loss, which occurs when the total intravesical pressure exceeds the maximal urethral pressure in the absence of detrusor activity. The patients suffering from stress incontinence lose urine during coughing, sneezing, physical activities, etc. Mixed incontinence is the combination of urge incontinence and stress incontinence.

The reported prevalences vary with the used methodology, terminology and definitions. Kok et al. [1] mentioned a prevalence of $23.5 \%$ in women of 60 years and over in a community based population. Daily loss was reported by $14 \%$. Other investigators found a prevalence of $57.1 \%$ in non-institutionalised women aged $45-70$ years. Women with urinary incontinence reported a decrease in physical functioning and vitality as compared with women without incontinence. Especially women with urge incontinence or stress and urge incontinence were impaired in quality of life [2]. Schulman et al. re-

John P.F.A. Heesakkers, MD

Department of Urology, UMC Nijmegen

PO Box 9101

NL-6500 HB Nijmegen (The Netherlands)

Tel. +31 24 3610871, Fax +3124 3541031, E-Mail j.heesakkers@uro.umcn.nl 
Fig. 1. Cross-section of the upper portion of a female sphincter [from ref. 44 with permission].

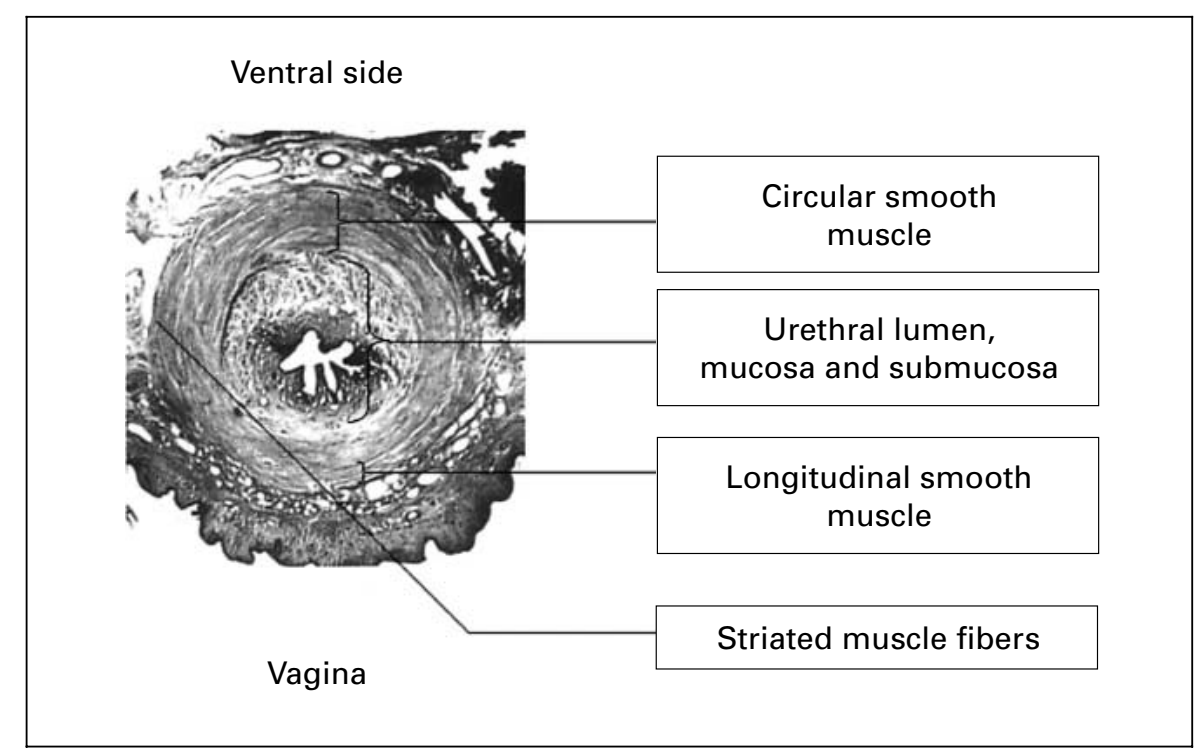

ported that $77 \%$ of incontinent patients were women. Incontinence affects one in five women aged over 50. It is considered invalidating by $30 \%$ of patients, whereas $40 \%$ of the patients conceal the problem [3]. Although there is a disparity in reported figures, in general one might say that the prevalence of incontinence is higher in women, peaks around the menopause and increases thereafter [4].

\section{Stress Urinary Incontinence}

Most patients with incontinence suffer from stress incontinence. The reported percentage of stress incontinent patients is up to $88 \%$ of all incontinent patients [5].

Stress incontinence is a problem of the closing mechanism of the bladder outlet. The closing mechanism of the bladder consists of sphincter structures that are responsible for the intrinsic urethral sphincter function and the structures that provide urethral support.

\section{Intrinsic Sphincter Function}

The female urethra and its sphincter components consist of the following functional structures: the sealing effect of the mucosa, most likely a closing bladder neck and a proper functioning urethral sphincter.

On the outside of a urethral cross-section circular striated muscle fibers are observed that are present in $80 \%$ along the total length of the urethra. The striated sphincter or rhabdosphincter surrounds the urethra completely but has a relatively thin diameter on the vaginal side. The muscle fibers are discontinuous at the dorsal side where they end in a tendon-like structure. During early age the muscular fibers at the dorsal side of the urethra are present, whereas these dorsal muscle fibers are lost later on [6].The two ends of the striated sphincter anchor at this tendon where they find firm support during contraction. This construction is important in the socalled Hammock theory (vide infra). In rats is observed that the striated muscle fibers insert in the connective tissue of the urethral wall. There is also overlap of the fibers in the midline. Another observation is that the insertion of the fibers on the ventral and dorsal side is not at the same level [7]. Although the main orientation of the striated urethral sphincter is circular, there are also longitudinal fiber directions. This could imply that closure of the urethra by the striated sphincter is done slitwise by compressing the ventral part against the dorsal part instead of closing in a purely circular way.

Going centrally a circular smooth muscle layer is found. Within this circular layer a thicker layer of longitudinally oriented smooth muscle is found. The urethral lumen is surrounded by the lamina propria and the urothelium. These latter two layers are under hormonal influence of estrogens. When functioning properly these layers provide the mucosal seal mechanism, responsible for one third of closure during rest [8]. The smooth muscle cells in the urethra are small and richly supplied with afferent and efferent nerve fibers. Elastic fibers are well developed in the bladder neck and urethra. A cross-sectional image is depicted in figure 1. 


\section{Innervation of the Intrinsic Urethral Sphincter}

The innervation of the urethra and urethral sphincter is from both somatic and autonomic pathways. Especially the pudendal nerve innervation is bilateral. This means that the urethral sphincter can be innervated from the right as well as the left pudendal nerve. Up to now, it is unclear whether bilateral innervation is important for urethral sphincter functioning. There are indications that asymmetry in sphincter innervation exists, but the clinical relevance is unclear [9]. The rhabdosphincter gets input from the S2-S4 nerve roots via the pudendal nerve. The neurons that innervate the urethral sphincter lie in the so called nucleus of Onuf in the sacral spinal cord. The intrapelvic somatic fibers travel along the anterior vaginal wall from the sacral segments S2-S4 to provide somatic supply to the pelvic floor [10]. The urethral muscles receive somatic information from the pudendal nerve entering from the perineum.

Autonomic innervation comes from the pelvic nerve that also originates at the sacral level $[11,12]$. It is likely that the functional innervation is somatic via the pudendal nerve and some modulation from the autonomic innervation occurs. The omega-shaped striated muscle in the human male extends from the perineal membrane to the apex of the prostate [13]. The innervation of the male external urethral sphincter is a point of controversy in the urologic literature. Dual somatic innervation of the rhabdosphincter is suggested; branches from the perineal nerve and an intrapelvic component that course nearby to the pelvic nerve [14]. The male urethral rhabdosphincter is innervated in part through special branches from the dorsal nerve of the penis after it splits from the pudendal nerve. Injury to these nerves may explain several features of post-prostatectomy urinary incontinence [15].

\section{Urethral Support Structures}

In order to function properly the urethral sphincter must be supported by a number of structures. Nowadays the main structures are thought to be the anterior vaginal wall, the pubourethral ligaments, tendinous arcus of the fascia pelvis, the endopelvic fascia and the pelvic diagram [7].

The endopelvic fascia connects the upper vagina, cervix and uterus to the lateral walls of the pelvis. The anterior vaginal wall is important in supporting the urethra and bladder base at the dorsal side. It constitutes a firm underground acting as a layer upon which the urethral sphincter can contract.
The pubourethral ligaments attach the midurethra to the pubic bone and prevent the downward movement of the urethra during pressure increase like coughing. The tendinous arc of the fascia pelvis is the structure where the muscle fibers of the levator ani and the pubococcygeus (together called the pelvic diagram) attach.

\section{Modern Theories on Stress Urinary Continence}

The above-mentioned supportive structures maintain the bladder base and urethra at an intrapelvic position during intra-abdominal pressure rise. Therefore the pressure increase exerted on the bladder can also be transmitted to the bladder neck and urethra. In this way the pressure increase is neutralized. This mechanism is called pressure transmission and was introduced by Enhorning [16] in 1961.

Nowadays, the general thinking is slightly different. As opposed to the completely passive concept of pressure transmission one supposes also an active part. DeLancey [17] introduced the hammock effect. This theory states that in order to function properly the intrinsic urethral sphincter must have a firm underground in order to contract and close the urethra. Therefore, the levator ani and the pubococcygeus muscle reflexly contract at the arcus tendineus of the fascia pelvic during sudden pressure rise. The dorsal backbone of the urethra contracts and stiffens. This creates the firm underground or hammock. This concept is depicted in figure 2 .

In 1990, the integral theory was introduced by Petros and Ulmsten [18]. They stated that a weak vagina is responsible for urge incontinence as well as stress incontinence. Continence is achieved by (a) contraction of the anterior part of the pubococcygeus muscle and the striated urethral sphincter; (b) elongation of the bladderneck by fixation of the proximal urethra against the vaginal wall, and (c) activation of the vaginal hammock. This implies that for continence, apart from the intrinsic sphincter, one needs proper functioning of the pubourethral ligaments, the vaginal hammock and the pubococcygeus muscles.

Incontinence caused by insufficient functioning of the intrinsic sphincter is called intrinsic sphincter deficiency (ISD). Classically, the fibrosed or pipe stem urethra is the cause of ISD. Other causes are denervation in neurogenic patients and estrogen deficiency. 
Fig. 2. The hammock theory as proposed by DeLancey. During sudden intra-abdominal pressure rise like during coughing, a reflex contraction of the pubococcygeus muscle occurs. This stretches and stiffens the vaginal hammock. This firm underground makes it easier for the urethral sphincter to close in a slitwise fashion onto this firm underground.

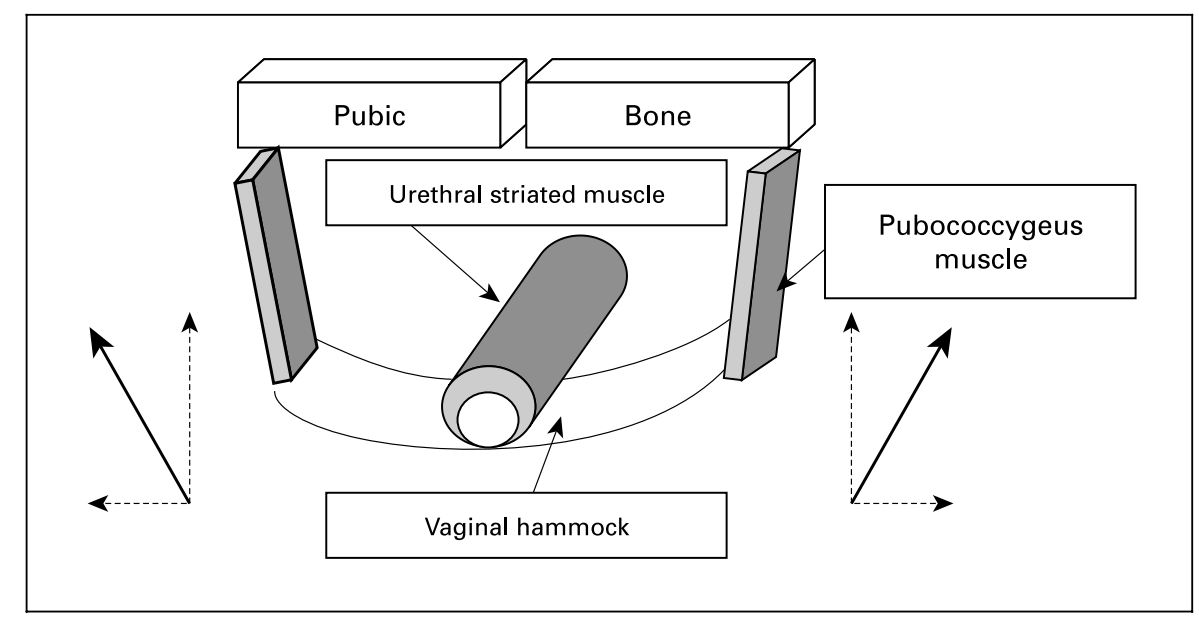

\section{ISD versus Urethral Hypermobility}

As mentioned above stress urinary incontinence is caused by either a combination of ISD and urethral hypermobility. Stress urinary incontinence (SUI) caused by ISD alone is rare whereas urethral hypermobility occurs frequently without SUI. The diagnosis of ISD and/ or urethral hypermobility theoretically can be made by diagnosis of bladder outlet function by means of urodynamic investigation. Bladder outlet structure or anatomy can be diagnosed by some imaging technique, like ultrasound, MRI or cystography. The gold standard for diagnosing stress urinary incontinence is the combination of functional and structural diagnoses. This means simultaneous urodynamic investigation and cystography combined in video-urodynamics [19]. Although video-urodynamics is often called the gold standard it is hardly ever used for diagnosing stress urinary incontinence [20].

It is relatively easy to determine the existence of urethral hypermobility with some imaging technique like lateral stress cystography, Q-tip test, etc.

The assessment of ISD is more difficult and often regarded as a diagnosis per exclusionem. One part of the urodynamic investigation is the urethral pressure profilometry or urethral pressure profile (UPP). With this technique the pressure within the urethra is measured by pulling a pressure catheter through the urethra with a constant speed, starting from the bladder side. During this movement the urethral sphincter is passed and the pressure appreciated. The point of highest urethral pressure is determined: the maximum urethral pressure or maximal urethral pressure (MUP). When the simultaneously measured intravesical pressure is subtracted from the MUP, the maximum urethral closure pressure (MUCP) is calculated. The MUCP gives the excessive pressure that is available for keeping the urethra closed during rest. The higher the MUCP is, the less the chance for stress incontinence. Normally the risk for SUI is highest during sudden intra-abdominal pressure rise, e.g. during coughing. Therefore, not only the resting UPP is important but also the stress UPP. The same UPP is made but in addition the patient is asked to cough 4-5 times during UPP measurement. At the cough spikes the ratio between intraurethral pressure and intravesical pressure can be determined. This ratio is called pressure transmission ratio (PTR) expressed in percent. PTR is derived from Enhornings theory [16]. When no urethral hypermobility exists the intra-abdominal pressure rise during e.g. coughing is exerted on the bladder as well as on the bladder neck. This implies that a neutralizing force at the bladder neck prevents the bladder from leaking at the same moment as the intra-abdominal pressure rise. Because of a reflex contraction of the pelvic floor the intraurethral stress pressure is often higher than the intra-abdominal stress pressure. This means that in patients where no urethral hypermobility exists, the PTR is more than $100 \%$.

The interpretation of the outcome of a UPP is that if the PTR is high $(>70-80 \%)$ no urethral hypermobility is present. If the PTR is $<70 \%$ urethral hypermobility might be present. This can be checked by imaging techniques. Regarding the MUCP, it is stated that a MUCP $<20 \mathrm{~cm}$ $\mathrm{H}_{2} \mathrm{O}$ is correlated with ISD. This figure comes from the observation that the outcome of a Burch colposuspension is poor in patients with a $\mathrm{MUCP}<20 \mathrm{~cm} \mathrm{H}_{2} \mathrm{O}$ [21].

To overcome the technical difficulties of UPP measurement Valsalva and cough abdominal leak point pres- 
sures (ALPP) have been proposed to differentiate ISD from urethral hypermobility. This means that the intravesical pressure during Valsalva or coughing is measured at the moment the patient looses urine. The interpretation is that an ALPP of $<65 \mathrm{~cm} \mathrm{H}_{2} \mathrm{O}$ is suggestive of ISD and ALPP $>100 \mathrm{~cm} \mathrm{H}_{2} \mathrm{O}$ is indicative of urethral hypermobility [22].

These cut-off points are that they are not validated and cannot be applied in individual cases. In practice this means that they are used as a control to see whether the diagnostic reasoning is right. In patients with pure urethral hypermobility the outcome of UPP and ALPP can be compared with the outcome of imaging. However, in patients with ISD no comparison exists. One can only state that when no urethral hypermobility is present and the patient is incontinent, ISD must be the cause of the incontinence. This makes the quest for a true diagnostic parameter of ISD more important.

To summarize, stress urinary incontinence is caused by the combination of ISD and urethral hypermobility. Although urethral hypermobility can be diagnosed by structural and functional investigations, ISD cannot. ISD so far is only a diagnosis per exclusionem: if a patient is incontinent and no hypermobility is observed, ISD must be present.

\section{Treatment of Stress Urinary Incontinence with Emphasis on Intrinsic Sphincter Deficiency}

The treatment of stress incontinence includes non-surgical modalities and surgical techniques. Because incontinence is not a life threatening disease but has a substantial impact on quality of life, the prime treatment goal is "non nocere'. Since all available treatment modalities cannot guarantee improvement and might even worsen the condition, one has to stay prudent.

It is a common practice to start with the least invasive treatment, which might provide success. If these noninvasive techniques fail or incontinence reoccurs after some time, the next step is to opt for a more invasive treatment. Among the non-surgical therapies are drug treatment, behavioral therapy like pelvic floor exercises or biofeedback, and nerve stimulation. The surgical therapies include periurethral and transurethral injection therapy, suspension operations, pubovaginal slings and artificial sphincters. Suspension therapies and the nowadays popular tension-free tapes mainly treat urethral hypermobility and are not primarily indicated for ISD. Therefore, they are not discussed here. Artificial urinary sphincters also are applied in ISD but mainly in the male population, which is beyond the scope of this project.

\section{Behavioral Therapy}

The theoretical basis of these physical therapies, as a treatment of pelvic floor muscle dysfunction associated with stress incontinence, is that facilitation and strengthening may improve efficiency of sphincteric action around the urethra. Training of the pelvic floor muscles may result in muscle hypertrophy, increasing the mechanical pressure on the urethra and may improve structural support of the pelvic organs [23]. Physical therapy consists of pelvic floor muscle exercise sometimes accompanied by tools as vaginal cones, biofeedback or electrical stimulation. Especially biofeedback provides meaningful physiological information directly to the patient about the use of various pelvic structures like pelvic floor and or urethral musculature. The goal is to focus attention on agonistic and antagonistic muscles in order to control and exercise both activities [24]. The ultimate goal is the isolated recruitment of the appropriate muscles in an effective way. Meticulous registration of the activity of isolated muscles is of importance in order to increase effectively the outcome of biofeedback.

Short-term cure rates or improvement rates of pelvic floor muscle exercises are reported to be only $60-70 \%$ [25]. Moreover, improvement only is most of the time the best result obtained. Cure is hardly ever achieved whereas patient motivation is essential for long-term success. Reviewing randomized clinical trials on conservative treatment of stress urinary incontinence, Berghmans et al. [26] conclude that there is strong evidence that pelvic floor muscle exercises are effective. They also conclude that biofeedback adjunct to pelvic floor muscle exercises is no more effective than pelvic floor muscle exercise alone. Others mention a trend for increased effectiveness of pelvic floor muscle exercises combined with biofeedback [27]. Several specialists in the field state that the success rates of biofeedback heavily lean on the quality of information fed back to the patient. In this perspective it could be important to have information about the quality of the pelvic floor muscles and the urethral sphincters. If there is a difference in strength or weaknesses in these muscles based on bilateral innervation differences, this could have implications for diagnosis and biofeedback therapy. If it is possible to register existing differences in strength, therapy could be focused on the weakest side in order to restore the balance.

The assumption is that a balanced quality in pelvic floor muscle strength and the urethral sphincter attributes 
to the continence mechanism. Regarding biofeedback a drawback can be perceived with the existing devices. The first is that it is not possible to register differentiated EMG recordings of the pelvic floor muscles and urethral sphincters. Discrimination between left and right and ventral and dorsal is not possible. This implies that a positive recording from the pelvic floor may come from the strongest muscle. The weak side therefore is disregarded or cannot be recognized. A false-positive signal is the result. Moreover, by performing muscle exercises with biofeedback, each time the signal from the strong muscle is fed back, muscle reinforcement of the strongest muscle is the result, without training the weakest one. Persisting incontinence might be the result.

If a device would be available that registers an EMG signal from different sites, more differentiated training by using differentiated biofeedback could improve the success rates of pelvic floor muscle training.

\section{Injectables}

The application of periurethral or transurethral injection therapy is the least invasive surgical treatment for stress urinary incontinence.

With this treatment a bulking agent is injected in the urethra at several sites in order to reinforce the closing capacity of the urethra. The theory is to facilitate coaptation of the urethral mucosa and to create some degree of outlet obstruction [28]. Various materials, including collagen, Teflon, fat, silicone, dextranomer in hyaluronic acid, ethylene vinyl polymer and also microballoons have been injected for treatment of intrinsic sphincter deficiency. As a routine the bulk material is injected at the 3, 6, 9 and 12 o'clock positions as defined by the view through a cystoscope. These positions are arbitrarily chosen.

The reported short-term cure rates range from 23 to $66 \%$ [29-32]. Improvement rates are higher, ranging from 33 to $74 \%$ [29-33]. The overall success rates, especially the long-term success rates are relatively poor, probably because the used bulk material migrates, like Teflon or silicone. Other material is reabsorbed, like collagen or fat. Another critical factor for success is the exact positioning of the bulk material. According to most authors it is essential not to place the bulk too deep because then the effect is minimal. On the other hand, a too superficial placement of an injectable might tear the urethra with consequent leaking of the material $[33,34]$. Since the urethral sphincter is regarded as a circumferential entity with equal quality at every position, the circumferential placement of the bulk injection has no specific role. If it could be determined it exactly at which location the sphincter is weakest, patients could profit from this information. The therapeutic consequences of differences in muscle strength or activity along the circumference of the sphincteric muscles could be that bulk material is injected at the site where the sphincteric muscle is weakest. This might increase the result of injection therapy.

\section{Assessment of Intrinsic Sphincter Function and ISD with Electromyography}

As described above, the functional diagnosis of ISD is based on a low MUCP or ALPP during urodynamic investigation in combination with a nonhypermobile urethra. With video-urodynamic investigation ISD is diagnosed when there is no bladderneck descent during intraabdominal pressure rise, the ALPP is low and the bladder is open while urinary loss is observed [22].

Other attempts to assess the function of the intrinsic sphincter can be done by EMG measurement. Normally EMG recordings of the urethral rhabdosphincter are done to see whether there is any sphincter activity during certain processes of the lower urinary tract, like voiding or storing of urine. It is used to see whether the urethral sphincter relaxes during voiding (synergic voiding) or contracts during voiding (dyssynergic voiding). In this way the coordination of voiding and non-voiding is assessed. This type of EMG measurement is called kinesiological EMG [35].

Together with other muscles of the pelvic floor, like the pubococcygeus muscle, the activity pattern of the urethral sphincter as well as the anal sphincter can be observed. There is continuous activity at rest and some increase during bladder filling. The latter implies that the urethral tone increases in order to prevent urine leakage. Reflex activity may be seen during sudden pressure increase like during coughing. There is urethral muscle relaxation during voiding, this also holds true for the pubocoggygeus muscle. Some publications found that the right as well as the left pubocoggygeus muscle act and relax together [36]. Kinesiological EMG measurement can tell you whether at some moment the investigated muscle is in an active state. It does not provide information about other sphincter features like generated force, activation of different parts of the sphincter etc.

Kinesiological EMG can be recorded with needle and surface electrodes. Needle EMG recording can be done with concentric needles and with single-fiber needle electrodes. Single-fiber EMG is a diagnostic tool for assessing defects of neuromuscular junction transmission and doc- 
umenting denervation following a lower motor neuron injury of S2-4. A single-fiber electrode is more selective than a concentric needle. Reinnervation can be best assessed with single-fiber EMG as extensive muscle atrophy results in insufficient MUPs to be evaluated with the concentric needle electrode [37].

Concentric needle electromyography (CN EMG) is valuable in the assessment of incontinence by providing quantification of MUPs, mapping external sphincter defects, and assessing reinnervation patterns. It can also be used to see at what part of the urethral sphincter activity exists at a certain moment and how this activity pattern propagates in time or what the contraction intensity is. This implies that the EMG pattern, the amplitude and the velocity of electrical activity can be detected. It can also give information about the spatial distribution of the electrical activity, and e.g. whether the midline is crossed from either the left or right side. Also areas without electrical activity like scar tissue in some sphincter parts can be observed with CN EMG [38]. The drawback of doing this is that one has to insert multiple needles in the urethral and/or anal sphincter in order to be able to register the activity. This is sometimes painful, difficult especially in the male urethral sphincter and artefacts may occur.

Surface EMG (S-EMG) allows information regarding the overall muscle function and condition to be collected from the mucosal surface of the urethral sphincter. The big advantage of S-EMG is that the sphincter features can be assessed without painful actions that also can disturb the recordings. The S-EMG signal reflects the spatial and temporal activity of many motor units of the muscle examined. An assumption of S-EMG is that the recorded potentials are originating from the underlying muscle. Electrical fields generated by larger muscles of the pelvic floor can contaminate the electrical field generated by the urethral sphincter. This phenomenon is called crosstalk.

Up to now urethral S-EMG is done with two ring electrodes mounted on a urethral catheter. With this technique one can record e.g. compound muscle action potentials (CMAP). These are responses evoked by direct stimulation of a nerve while recording the signals from the innervated muscle. The small action potentials from individual fibers are summated to generate one large CMAP when all fibers are activated synchronously [39]. This implies that one can detect muscle activity from the sphincter. However, one cannot tell whether this activity is coming from the right or left side, whether there is crossing of the midline, etc.

Theoretically, with surface EMG several features of the urethral sphincter can be assessed. It would be of great value if EMG could predict and/or classify ISD or the severity of ISD. With aids like S-EMG one could also perhaps make a better choice of therapy. So far only limited attempts have been made to use urethral EMG measurement for therapeutic decisions [40].

\section{Future Directions in Urethral EMG Measurements}

One step further could be that one tries to identify those areas of the urethral sphincter with improper functioning or those areas that are innervated asymmetrically. The theory behind this development is that proper urethral sphincter functioning needs symmetrical innervation from both left and right pudendal nerves. If the nerves are acting symmetrically, the stimulation of the sphincter from both sides gives a simultaneous contracting sphincter. If one part of the sphincter would not contract due to fibrosis or due to lack of innervation from one side, that part of the improper functioning sphincter could be the cause of urinary incontinence. One can assume that taking therapeutic measures of this lacking sphincter part could have beneficial effect on the patient's continent state. Following this line of reasoning it could be rational to inject bulking agents at the weakest spot of the urinary sphincter. On the other hand one can also imagine that compensating mechanisms can occur. If the left or right pudendal nerve is not functioning the other (dominant) side could compensate this loss. This can occur when the innervation signals come from one side but also cross the midline and innervate the contralateral sphincter part as well. If this would be known one can also imagine that damage to the dominant pudendal nerve would cause complete ISD whereas damage to the other pudendal nerve would have no effect. This could be of importance e.g. during the side chosen for episiotomy during childbirth.

To diagnose those parts of the urethral sphincter without electrical activity or to record the way in which innervation patterns affect the electrical activity of the urethral sphincter, S-EMG could be used. For this application ring electrodes cannot be used. If at the circumference of the urethral sphincter separate electrodes could be placed that measure the activity at one point. In this way one could see how the spatial distribution is around the urethral sphincter, where the innervation signals come, where the intensity of urethral sphincter activity is the highest, what the conducting velocity is, whether the signals cross the midline etc. This kind of information could be valuable to 

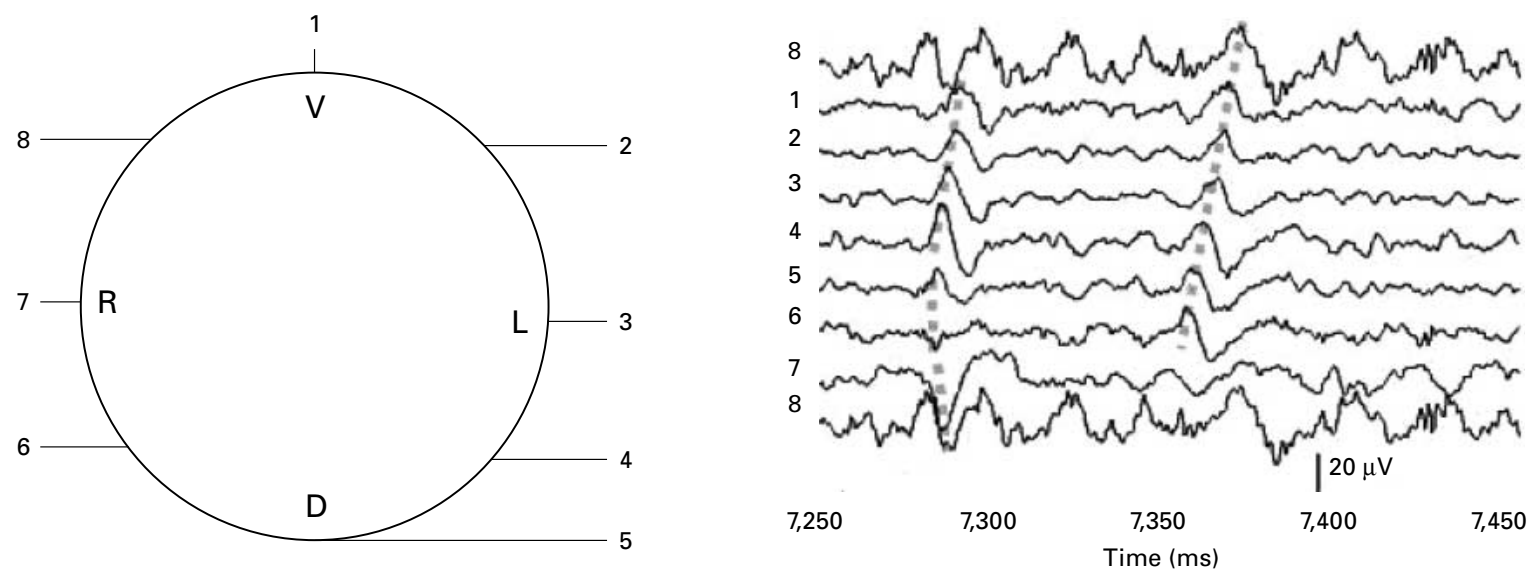

Fig. 3. Circumferential S-EMG from the urethral sphincter. This recording is done with a circular array of 8 contacts and therefore 7 differential signals. Channel 1 is in the ventral position and channel 5 is in the dorsal position. A scheme of the contacts' position is drawn on the left side. It can be seen that the motor units propagate from channels 4 and 6 to channels 1 and 8 . This implies that in this subject the innervation signals come in from both the left and right dorsal sides and propagation is in the ventral direction [from ref. 41].

have insight in the severity and cause of ISD and also the therapeutic consequences. It has been proven already that it is feasible to have circumferential S-EMG recordings from the urethral sphincter [41, 42]. Figure 3 demonstrates how the three motor units are detected during circumferential S-EMG measurement of the urethral sphincter [for more details, see 43].
The above recordings are examples of the feasibility of circumferential S-EMG measurement in human urethral sphincters.

The near future hopefully will give the data that make it possible to correlate the S-EMG signals with diagnosis and treatment of ISD in males as well as females.

\section{References}

1 Kok A, Voorhorst F, Burger C, Van Houten P, Kenemans P, Janssens J: Urinary and faecal incontinence in community-residing elderly women. Age Ageing 1992;21:211-215.

2 Van der Vaart C, De Leeuw J, Roovers J, Heintz A: De invloed van urine-incontinentie op de kwaliteit van leven bij thuiswonende Nederlandse vrouwen van 45-70 jaar. Ned Tijdschr Geneeskd 2000;144:894-897.

3 Schulman C, Claes H, Matthijs J: Urinary incontinence in Belgium: A population-based epidemiological survey. Eur Urol 1997;32: 315-320.

4 Hampel C, Wienhold D, Dahms S, Thüroff JW: Heterogeneity in epidemiological investigations of bladder control problems: A problem of definition. Br J Urol Int 1999;83(suppl 2):10-15.
5 Sandvik H, Hunskaar S, Vanvik A, Braat H, Seim A, Hermstad R: Diagnostic classification of female incontinence: An epidemiological survey corrected for validity. J Clin Epidemiol 1995;48:339-343.

6 Peruchini D, Delancey J, Patane L: The number and diameter of the striated muscle fibres in the female urethra. Neurourol Urodyn 1997; 16:405-407.

7 Haab F, et al: Functional anatomy of the bladder and the urethra in females; in Corcos $\mathrm{J}$, Schick E (eds): The Urinary Sphincter. New York, Marcel Dekker, 2001, pp 15-24.

8 Rud T, Andersson KE, Asmussen M, Hunting A, Ulmsten U: Factors maintaining intraurethral pressure in women. Invest Urol 1980;17: 343-347.
9 Deletis V, Vodusek DB, Abbott R, Epstein FJ, Turndorf $\mathrm{H}$ : Intra-operative monitoring of the dorsal sacral roots: Minimizing the risk of iatrogenic micturition disorders. Neurosurgery 1992;30:72-75.

10 Borirakchanyavat S, Aboseif SR, Carroll PR, Tanagho EA, Lue TF: Continence mechanism of the isolated female urethra: An anatomical study of the intrapelvic somatic nerves. J Urol 1997; 158:822-826.

11 Elbadawi A, Schenk EA: A new theory of the innervation of bladder musculature. 2. Innervation of the vesicourethral junction and external urethral sphincter. J Urol 1974;111:613615.

12 Hollabaugh RS, Steiner MS, Dmochowski RR: Neuroanatomy of the female continence complex: Clinical implications. Urology 2001;57: 382-388. 
13 Brooks JD, Chao WM, Kerr J: Male pelvic anatomy reconstructed from the visible human data set. J Urol 1998;159:868-872.

14 Hollabaugh RS Jr, Dmochowski RR, Steiner MS: Neuroanatomy of the male rhabdosphincter. Urology 1997;49:426-434.

15 Narayan P, Konety B, Aslam K, Aboseif S, Blumenfeld W, Tanagho E: Neuroanatomy of the external urethral sphincter: Implications for urinary continence preservation during radical prostate surgery. J Urol 1995; 153:337-341.

16 Enhorning G: Simultaneous recording of intravesical and intra-urethral pressure: A study on urethral closure in normal and stress incontinent women. Acta Chir Scand 1961;(suppl 276):1-68.

17 DeLancey JOL: Structural support of the urethra as it relates to stress urinary incontinence: The hammock hypothesis. Am J Obstet Gynecol 1994;170:1713-1720.

18 Petros P, Ulmsten U: An integral theory of female urinary incontinence: experimental and clinical considerations. Acta Obstet Gynecol Scand 1990;153:7-31

19 Bates CP, Whiteside CG, Turner-Warwick R: Synchronous cine-pressure-flow-cysto-urethrography with special reference to stress and urge incontinence. Br J Urol. 1970;42:714-723.

20 Chapple C, Wein A, Artibani W, Brubaker B, Haab F, Heesakkers J, Lightner D: Critical review and opinion of diagnostic studies for sphincteric incontinence in the female, in press.

21 Sand PK, et al: The prognostic significance of augmentation of urethral closure pressure and functional urethral length. Int $\mathrm{J}$ Gynaecol Obstet 1990;33:135-139.

22 McGuire EJ, Cespedes RD, Cross CA, O'Connell HE: Videourodynamic studies. Urol Clins N Am 1996;23:309-321.

23 Bo K: Pelvic floor muscle exercise for the treatment of stress urinary incontinence: An exercise physiology perspective. Int Urogynecol J 1995;6:282-291.

24 Bourcier A, Juras J: Nonsurgical therapy for stress incontinence. Urol Clins N Am 1995;22: 613-627.
25 Wilson P, Samarrai T, Deakin M, Kolbe E, Brown A: An objective assessment of physiotherapy for female genuine stress incontinence. Br J Obstet Gynecol 1987;94:575-582.

26 Berghmans L, Hendriks H, Bo K, Hay-Smith E, de Bie R, van Waalwijk van Doorn E: Conservative treatment of stress urinary incontinence in women: A systematic review of randomized clinical trials. Br J Urol 1998;82:181191.

27 De Kruif Y, Van Wegen E: Pelvic floor muscle exercise therapy with myofeedback for women with stress urinary incontinence: A meta-analysis. Physiotherapy 1996;82:107-113.

28 Kobashi K, Leach G: Stress urinary incontinence. Curr Opin Urol 1999;9:285-290.

29 Herschorn S, Steele D, Radomski S: Follow-up of intraurethral collagen for female stress urinary incontinence. J Urol 1996;156:13051309.

30 Pycha A, Klinger C, Haitel A, Heinz-Peer G, Marberger M: Implantable microballoons: An attractive alternative to the management of intrinsic sphincter deficiency. Eur Urol 1998; 33:469-475.

31 Dmochowski R, Herschorn S, Corcos J, Karram M, Pommerville P, Berger Y, et al: Multicenter randomized controlled study to evaluate uryx urethral bulking agents in treating female stress urinary incontinence. Proc Int Continence Society (ICS), Heidelberg, 2002, p 187.

32 Lightner D, Calvosa C, Andersen R, Klimberg I, Brito CG, Snyder J, et al: A new injectable bulking agent for treatment of stress urinary incontinence: Results of a multicenter, randomized, controlled, double-blind study of Durasphere. Urology 2001;58:12-15.

33 Cross C, English S, Cespedes R, McGuire E: A follow-up on transurethral collagen injection therapy for urinary incontinence. J Urol 1998; 159:106-108.

34 Winters J, Appell R: Periurethral injection of collagen in the treatment of intrinsic sphincteric deficiency in the female patient. Urol Clins N Am 1995;22:673-678.
35 Deindl FM, Vodusek DB, Hesse U, Schussler B: Pelvic floor activity patterns: comparison of nulliparous continent and parous urinary stress incontinent women: A kinesiological EMG study. Br J Urol 1994;73:413-417.

36 Deindl FM, Vodusek DB, Hesse U, et al: Activity patterns of pubococcygeal muscle in nulliparous continent women. Br J Urol 1993;72: 46.

37 Olsen AL, Benson JT, McClellan E: Urethral sphincter needle electromyography in women: Comparison of periurethral and transvaginal approaches. Neurourol Urodyn 1998;17:531535

38 Podnar S, Rodi Z, Lukanovic A, Trsinar B, Vodusek DB: Standardization of anal sphincter EMG: Technique of needle examination. Muscle Nerve 1999:22:400-403.

39 Benson JT: Electrophysiological monitoring of sacral nerve stimulation; in Jonas U, Grunewald V (eds): New Perspectives in Sacral Nerve Stimulation. New York, Martin Dunitz, 2002, pp 107-115.

40 Fischer JR, Hale DS, McClellan E, Benson JT: The use of urethral electrodiagnosis to select the method of surgery in women with intrinsic sphincter deficiency. Int Urogynecol 2001; (suppl 1):33.

41 Dongen E, Merletti R, Heesakkers J, Wijkstra $\mathrm{H}$, Enck P: Introducing OASIS (On Asymmetry In Sphincters) and surface EMG of sphincters. Proc Int Continence Society (ICS), Heidelberg, 2002, vol 169, p 93.

42 Gerretsen R, Cescon C, Farina D, Wijkstra H, Heesakkers J: Detection of innervation zones and innervation zone distribution in the urethral sphincter through circumferential surface EMG. Proc Int Continence Society (ICS), Florence, 2003, vol 164, p 43.

43 Merletti R, Bottin A, Cescon C, Farina D, Gazuzoni M, Martina S, Mesin L, Pozzo M, Rainoldi A, Enck P: Multi-channel surface EMG for the non-invasive assessment of the anal sphincter muscle. Digestion, in press.

44 Tichy M: The morphogenesis of human sphincter urethrae muscle. Anat Embryol 1989;180: $577-582$.
Urinary Incontinence and Sphincter

Functioning
Digestion 2004;69:93-101 